\title{
Values and competencies in the school of the future
}

\author{
Humberto Maturana and Eduardo Cabezon \\ Facultad de Ciencias, Universidad de Chile, Santiago, Chile. \\ Universidad Metropolitana de Ciencias de la Educacion (UMCE), \\ Av. Jose Pedro Alessandri 774, Ñuñoa, Santiago, Chile. \\ ecabezon@umce.cl
}

\begin{abstract}
The purpose of this paper is to present a concept of education that stems from the theory of cognition of one of the authors. From this concept the values and competencies (abilities and skills) are proposed that the School of the Future ought to develop as a new learning environment. The following basic statement is discussed: "Education is a process by means of which adequate relational behaviors (i.e. cognitive, affective and psychomotor behaviors) are triggered through which another (or oneself) arises as a legitimate other in coexistence with oneself." If this emotion is conserved as the fundamental culture that we live together, it is more likely to observe an educational environment in which human beings (adults and children) can live together in autonomy, responsibility and respect for themselves, for others, and for their ecological environment. If these conditions are fulfilled, human actions will be developed with trust and mutual acceptance. We can expect that within this educational and learning environment, persons will interact with enthusiasm in their daily life, they will show creativity when proposing new ideas, ability to assess themselves with equity and to conserve their adequate social behaviors with responsibility and self-respect.
\end{abstract}

Keywords: Culture, languages, learning environment

\section{INTRODUCTION}

Different cultures vary according to different configurations of emotions that characterize them as different closed networks of conversations. What

The original version of this chapter was revised: The copyright line was incorrect. This has been corrected. The Erratum to this chapter is available at DOI: 10.1007/978-0-387-35403-3_29 
characterizes the different behaviors as different kinds of actions, are the different emotions under which they arise or are received.

We claim that living under the emotion of love, i.e. under those relational behaviors through which another (or oneself) arises as a legitimate other in coexistence with oneself, we can expect intelligent behaviors. That, which we call intelligence in daily life in our culture, is an expression of an assessment of the capacity to participate in a new or an old consensual domain that a person, or in general any living being, may exhibit in the course of its interactions. In all cases of intelligent behaviors, the biological condition that makes those different intelligent behaviors is the same: structural plasticity as the fundament for a changing adequate behavior in a changing medium.

In order to understand more deeply the fundamental notions of this paper, we firstly present some of the ideas that have been developed by one of the authors, Humberto Maturana, who has rooted his research from biological and systemic thinking and experiments.

\section{THE LIVING SYSTEMS}

In 1970 the word "autopoiesis" was introduced (Maturana and Varela, 1972 ) in order to connote the organization of living systems as closed networks of molecular production. The fundamental thing that happens in the constitution of a living system as a molecular autopoietic system is its constitution as an autonomous entity that has a singular existence as such in the continuous flow of molecules through it. Biological phenomena occur in the actual realization of living systems as singular unites, not in the particular nature of any of the molecular processes that realize them. "Autopoiesis" is not something that can be called a property of living systems. Rather it is their actual manner of being as the organization that constitutes them as singular entities in the molecular space.

The claim that living systems exist as singular autonomous molecular autopoietic unites through interactions in a medium with which they are in a continuous molecular interchange, is a claim about how they exist in their internal composition as well as about how they exist as totalities. Systems as composite entities have a dual existence, namely, they exist as singularities that operate as simple unites in the domain in which they arise as totalities, and at the same time they exist as composite entities in the domain of the operation of their components. The relation between these two domains is not causal. They do not intersect, nor do the phenomena, which pertain to one, occur in the other. The generative relation between the two as seen by an observer is a historical relation. The totality arises together with the 
relational domain in which they exist as such. More details about these statements can be found in Maturana (1980, 1988 and 1990).

\subsection{Language and languaging}

That which we connote as we speak of language is usually seen in terms of what we do while "languaging" (using language), and therefore, we usually speak of language as if it is an instrument we use to communicate. Thus, it seems acceptable to say that language is a symbolic system of communication. But language cannot be explained in terms of notions such as communication or symbolization, because these notions refer to operations that entail language. Communication is a commentary about the flow of the interactions between systems. Also symbolization is secondary to language, because it takes place in the explicit distinction that one particular operation will participate in the flow of the co-ordinations of behaviors for some other operation in such a flow. Languaging occurs in the flow of recursive co-ordinations of doings, not in any isolated coordination of doings in particular. Language arises as a manner of living together in a new operational domain that did not exist before.

Human beings exist in language. That means that they are the kind of beings that operate in a manner contingent to the course of our languaging in the flow of our recursive "consensual co-ordinations of consensual coordinations of behaviors". In other words, human beings exist in closed dynamics of languaging, and everything that they do as humans takes place in our languaging as a flow of consensual co-ordinations of consensual coordinations of behaviors. For example, a minimal operation in languaging in which we may understand what this means, takes place when one attempts to take a taxi through gestures. If one meets the gaze of a taxi driver on the other side of the street and makes a gesture to stop him, and then one makes another gesture indicating to him to do a U-turn around, what one does is coordinating the first consensual coordination. Actually, what has happened is an operation of coordination of coordination of behaviors in which the taxi as a carrying operation had arisen. The meeting of the gazes by the first gesture constituted an interaction in which the client and the taxi driver entered in an initial coordination of behavior. While the gesture of the client as seen by the taxi driver, coordinated such initial coordination in a sequence that an observer would call an act of hiring the taxi, so the next gesture for turning around was the coordination over the first coordination of behavior.

As languaging beings, living immersed in languaging, we do not easily see that in this episode two things have happened. One is the flow in coordinations of co-ordinations of behavior that are not innate, but are consensual (that is, learned). The second thing is that the taxi as a carrying 
device arises in the coordination of coordination of behavior, and is not an independent entity by itself. So, all that we say or may say, all that we may distinguish as we do what we do as observers (as human languaging beings), takes place as an operation in consensual co-ordinations of behaviors, without making any reference to anything outside our languaging.

\section{$2.2 \quad$ Emotions}

What we distinguish in daily life as emotions are all kinds of relational behaviors, not particular doings. And what we connote biologically as we speak of emotions referring to ourselves or to other animals, are body dynamic dispositions (involving the nervous system and the whole body). They determine what we can do or not do, in what relations we can enter or not enter, at any moment. As a result, different emotions can be fully characterized as different domains of relational behaviors or as dynamic body dispositions for relational behaviors. For example, love is the domain of those behaviors or dynamic body dispositions through which another arises as a legitimate other in coexistence with oneself. Aggression is the domain of those behaviors or dynamic body dispositions through which another is denied as a legitimate other in coexistence with oneself. And fear is the domain of those behaviors or dynamic body dispositions through which one moves away from the circumstances in which one finds oneself. In these circumstances, love is not a virtue or something special. It simply is a biological phenomenon as the domain of those behaviors through which social life arises and is conserved. Love is the biological dynamic system that constitutes trust and mutual acceptance in body and spiritual relations of nearness and intimacy.

\section{HUMANS AS LANGUAGING AND LOVING ANIMALS}

Humans are languaging animals. That means that they live in language as a manner of flowing in coexistence in consensual co-ordinations of consensual co-ordinations of behaviors. This manner of living must have arisen in the history that gave origin to humans some three million years ago. At the same time humans are loving animals. That is apparent in daily life in that they fall ill, at any age, when they are deprived of love because of demands, pressures or any relational behavior that denies them. Gerda Verden-Zöller (1993) has shown in her studies of the early childhood, that it is fundamental for a child to grow in a relation of total trust and body 
acceptance in free play. At first in the relation with the mother (female or male, since mother is a relation of care), and then as the child grows in relation to other persons with which he or she lives (in nursery, kindergarten and school), to become a self-respecting and socially integrated adult.

The evolutionary history of human lineage is a history of social life centered on consensuality and cooperation, not on competition or aggressive strife. As such human evolutionary history is a history of expansion of the capacities for consensuality, and hence, of expansion of intelligence. Intelligence is not primarily the capacity to solve problems, but it is the capacity to participate in the generation, expansion and operation in consensual domains as domains of co-ordinations of behaviors through living together. Languaging, indeed, living in conversations as humans do, requires such an enormous capacity for consensuality, that humans are all essentially equally intelligent. The differences in intelligence that seem to exist between humans are not due to differences in their capacity for consensuality, but in their "emotioning" (having emotions). In fact, due to the nature of intelligence as a relational biological phenomenon, different emotions affect it differently. Thus, ambition, competitiveness, anger, envy, aggression and fear reduce intelligence because they restrict the domain of openness for consensuality. Only love expands intelligence, because love as the domain of those behaviors through which the other arises as a legitimate other in coexistence with oneself, opens a human being to see and to enter in collaboration.

\subsection{Culture}

When we speak of culture or cultural affairs in daily life, we mean a closed network of conversations. That network constitutes and defines a manner of human living as a network of co-ordinations of emotions and actions that is realized as a particular configuration of interlacing of doings and emotions of the people that live that culture. As such, a culture is constitutively a closed conservative system that generates its members as they realize it through their participation in the conversations that constitute and define that culture. To pertain or belong to one culture is an operational condition, not an intrinsic quality or a constitutive condition of the human beings that realize that culture. Any human being can belong to different cultures in any different circumstances of his or her living, according to the conversations in which he or she participates in those different moments. 


\subsection{Values}

"Values are distinctions of relational configurations in the living together, which obtain their legitimacy from love" (Maturana, 1990). Values can also be understood as linguistic commentaries that missed the particular aspects of living together under the inspiration of love. All the values referred to in the literature are founded in love, such as honesty, cooperation, respect, loyalty, generosity, responsibility, justice. Why does in our cultural environment the necessity arises to identify and establish explicitly the values that we would like to live? One explanation from our perspective is that this is due to the fact that we belong to a particular culture (patriarchal culture) which has a fundamental contradiction, which in great proportion is the source of the suffering in which we live now. In other words, our present culture is the encounter of two cultures based on emotions which contradict to each other. One is the ancestral "matristic" (not "matriarchal") culture founded in the emotion of love. The other is the patriarchal culture, which was initiated with shepherdess some ten thousand years ago, founded in the negation of the other, that emphasized relationships of appropriation, competitiveness, struggle, success and control, in contrast to the values lived in the relation of child and mother. This negation of what was learned in infancy that arises in adulthood, gives origin to suffering. Thus the question about values arises from living within this contradiction, as a reflection to recover the matristic life of the infancy for the life of adulthood.

\section{EDUCATION FOR THE FUTURE}

First of all, we have to state that from this biological point of view, to learn is to live together. That means that the learning happens in any way the transformation that takes place in the living together. Human beings, for their condition of living in language, are open to learn anything. However, not every learning can be considered as educative. The term "education" is derived from the action that takes an implicit ethical sense. The ethical preoccupations are related to living in a free and non-contradictory environment, under the mutual acceptance and respect. Meanwhile, the moral preoccupations have to do with social norms, which have been established as legitimate by an authority. The norms of actions are not necessarily accepted with enjoyment. It is more likely that what is realized from the inspiration of love and reflection, can permit us to act with freedom, and then develops as a responsible act from our understanding. 


\subsection{Values, competencies in a new learning environment}

We think that probably now our basic statement about education could be understood in the following terms: "Education is a process by means of which adequate relational behaviors (i.e. cognitive, affective and psychomotor behaviors) are triggered. Through that another (or oneself) arises as a legitimate other in coexistence with oneself." This means under the emotions of love. Maybe this simple statement might also be considered simplistic. But our experience with different kinds of students and with teachers is that they have understood that their most important task is to live together with others in the acceptance of themselves as legitimate others. Finally, if the emotion of living in love is conserved as the fundamental culture, it is more likely to observe an educational environment in which human beings (adults and children) can live together in autonomy, responsibility and respect for themselves, for others and for their ecological environment. If these conditions are fulfilled, human actions will be developed with trust and mutual acceptance. We can expect that within this learning environment, persons will interact with enthusiasm, they will show creativity when proposing new ideas, ability to assess themselves with equity and to conserve their social behaviors with responsibility and self-respect.

\subsection{The role of ICT in future education and schools}

Under these conditions ICT will not be a problem for education. On the contrary, we could use ICT as an expansion of our body in terms of mutual trust and acceptance. We claim that from our experiences for the last 8 years, working with teachers and students. Our actual work has been done mainly with teachers in the Master Program of Education at the "Universidad Metropolitana de Ciencias de la Educacion" (UMCE) in Santiago, since 1992. Every year we have had some 30 teachers as graduate students in each semester in our course named "Biology of Knowing and Biology of Love".

This course, with a duration of 18 weeks, consists of lectures and workshops, which permit the students to understand and reflect about the ideas expressed in this paper. In the beginning we usually hear from the students that these ideas cannot be applied to education. Around the middle of the course, we observe that many teachers can apply in some creative and personal way the discussed strategies. For example, we see the application of one of the main notions of the biology of cognition that "in the experience one cannot distinguish between perception and illusion", and that then that errors or mistakes are not committed "a priori", but afterwards as a commentary of one observer. We think that these ideas can be understood in a way that many of the teachers can really apply procedures of formative 
evaluation on their students in different. If these relatively simple interactions that before seemed difficult to apply, are easily applied after a few weeks, we think that the emotioning that we can elicit from these students with the understanding of the basics of the theory of cognition, are good signs for teachers to be open to operate with more enthusiasm with ICT devices at their schools, than their colleagues without this experience.

We are beginning to follow up our teachers in their actual environment. Some proportion of them, after their graduation as Master of Education, have been promoted as supervisors giving technical support in their schools. Our hypothesis is that when some theory is provided on reflection and understanding under the emotions of love, it is more likely that the students can operate in daily life and in their professional activities with more freedom in a creative way.

\section{REFERENCES}

Maturana, H. and Varela, F. (1972) De Máquinas y Seres Vivos, Editorial Universitaria, Santiago, Chile.

Maturana, H. and Varela, F. (1980) Biology of Cognition, in Autopoiesis and Cognition, edited by D. Reidel.

Maturana, H. (1988) Reality: The Search for Objectivity or the Quest for a Compelling Argument. Irish Journal of Psychology (Issue on Constructivism) 9 (1): 25-82.

Maturana, H. (1990) Science and Daily Life: The Ontology of Scientific Explanations. In: Self- Organization: Portrait of a Scientific Revolution, W. Krohn, G. Kuppers (eds.) Kluwer Academic Publishers, Dordrecht, Boston, London.

Verden-Zöller, G. and Maturana, H. (1993) Amor y Juego: Fundamentos Olvidados de lo Humano, Instituto de Terapia Cognitiva, Santiago, Chile.

\section{BIOGRAPHIES}

Humberto Maturana is professor in biology at the Universidad de Chile as a specialist in perception, neurobiology and cybernetics. He teaches at the Universidad Metropolitana de Ciencias de la Educacion (UMCE) in the graduate program for teachers. He invented the notion of "autopoiesis" applied to the living systems and his theory of cognition has been applied in education since 1989. In 1994 he won the National Prize of Science in Chile.

Eduardo Cabezon is a professor in evaluation and curriculum at the Universidad Metropolitana de Ciencias de la Educacion (UMCE). He has been working with Humberto Maturana since 1990 and is applying the theory of cognition in his undergraduate and graduate teaching and research. 